\title{
Changes in serum concentration of rilpivirine in an HIV-infected patient treated with a combination therapy of hemodialysis and peritoneal dialysis
}

Nanako Oshiro ${ }^{1}$, Kentaro Kohagura ${ }^{2 *}$ (D), Shoji Tsuneyoshi ${ }^{3}$, Masao Tateyama ${ }^{4}$, Ryo Zamami ${ }^{2}$, Hitoshi Uehara ${ }^{5}$, Jiro Fujita ${ }^{4}$ and Yusuke Ohya ${ }^{1}$

\begin{abstract}
Background: To our knowledge, there are no preexisting reports concerning rilpivirine (RPV) removal by hemodialysis and peritoneal dialysis.

Case presentation: This study aimed to evaluate the effect of hemodialysis and peritoneal dialysis on plasma concentrations of RPV in a 45-year-old man infected with HIV and exhibiting end-stage renal disease (ESRD). The extraction ratio of RPV by hemodialysis was $4.5 \%$. Plasma concentrations of RPV remained far above the proteinbinding-adjusted inhibitory levels during a combination therapy of hemodialysis and peritoneal dialysis. Our results suggest minimal RPV removal via hemodialysis and peritoneal dialysis with no specific dosage adjustments required in an HIV-infected patient undergoing this combination therapy.

Conclusion: In conclusion, this study showed that RPV administered without dose adjustment resulted in steadystate plasma drug concentration in an HIV-infected patient treated with a combination therapy of hemodialysis and peritoneal dialysis.
\end{abstract}

Keywords: Rilpivirine, Pharmacokinetic, HIV, Dialysis, Peritoneal dialysis, CART

\section{Background}

The prognosis of HIV-infected end-stage renal disease (ESRD) patients treated by maintenance dialysis was dismal in the early 1980s but has improved remarkably since then due to highly effective combined antiretroviral therapy (cART) [1]. Therefore, the prevalence of HIV-infected patients requiring renal replacement therapy (RRT) for ESRD continues to increase around the world [2]. Dialysis therapy is used to treat chronic uremia and remove toxic waste products that accumulate in ESRD patients. However, this technique removes

\footnotetext{
* Correspondence: kohagura@med.u-ryukyu.ac.jp

${ }^{2}$ Dialysis Unit University of the Ryukyus Hospital, Okinawa, Japan

Full list of author information is available at the end of the article
}

drug as well as waste compounds. Therefore, it is important for clinicians to understand the pharmacokinetic disposition of these compounds in ESRD patients.

In Japan, the number cases in which RRT has been introduced to HIV-infected patients is around 100 and is expected to increase in the future [3]. The choice for RRT should depend on the individual patient's lifestyle, preference, and availability of family and other support, and not be based on HIV seropositivity [1]. It is reported that no difference in patient survival was found between peritoneal dialysis versus hemodialysis (hazard ratio, 1.01; 95\% confidence interval, 0.91 to 1.13 , respectively) [4].

C C The Author(s). 2020 Open Access This article is licensed under a Creative Commons Attribution 4.0 International License, which permits use, sharing, adaptation, distribution and reproduction in any medium or format, as long as you give appropriate credit to the original author(s) and the source, provide a link to the Creative Commons licence, and indicate if changes were made. The images or other third party material in this article are included in the article's Creative Commons licence, unless indicated otherwise in a credit line to the material. If material is not included in the article's Creative Commons licence and your intended use is not permitted by statutory regulation or exceeds the permitted use, you will need to obtain permission directly from the copyright holder. To view a copy of this licence, visit http://creativecommons.org/licenses/by/4.0/ The Creative Commons Public Domain Dedication waiver (http://creativecommons.org/publicdomain/zero/1.0/) applies to the data made available in this article, unless otherwise stated in a credit line to the data. 
There remain few reports related to the pharmacokinetics of anti-HIV drugs in dialysis patients. To prevent anti-HIV drug resistance, maintaining blood levels of anti-HIV drugs is extremely important. In Japan, cART accompanied by peritoneal dialysis and hemodialysis is widely performed, but there are also few reports on pharmacokinetics within these combined therapies.

Rilpivirine (RPV) and dolutegravir (DTG), a nonnucleoside reverse transcriptase inhibitor (NNRTI) and an integrase stand transfer inhibitor (INSTI), respectively, are being administered without dosage adjustment in HIV-infected end-stage ESRD patients. Both of these drugs have appeared on the market since 2010. There are reports concerning conventional drugs and the impact of dialysis on the pharmacokinetics of the antiretroviral drugs used to treat HIV [5]. Although the antiviral activity of DTG is known to be retained upon its elimination by hemodialysis [6], no reports exist on the pharmacokinetics of RPV in ESRD patients.

Renal excretion of RPV and DTG both having a lowmolecular weight is $<1 \%$ and their protein binding rates are $99.7 \%$ and $99.3 \%$, respectively $[6,7]$. These findings suggest that removal of such drugs in plasma by hemodialysis and peritoneal dialysis may be small. Therefore, as little information is available regarding these drugs during the aforementioned treatment conditions, we evaluated the effect of hemodialysis and peritoneal dialysis on concentrations of RPV and DTG in HIV-infected patients with ESRD.

\section{Case presentation}

We report herein the case of a 45-year-old man who was diagnosed as having HIV-associated nephropathy (HIVAN) in addition to diabetic nephropathy. He was known to be infected with HIV-1 at 36 years old. The patient elected for combined therapy with peritoneal dialysis and hemodialysis as RRT, and commenced treatment with a combination therapy of hemodialysis and peritoneal dialysis a month prior to this study. He was treated once a day with each of the following drugs: abacavir (ABC, $600 \mathrm{mg}$ ), DTG (50 mg), and RPV (25 mg). In addition to cART therapy, the patient was treated with angiotensin-receptor blocker (azilsartan $10 \mathrm{mg} /$ day), diuretics (furosemide, $40 \mathrm{mg} /$ day; torasemide, 8 $\mathrm{mg} /$ day), iron supplement (ferrous citrate, $1500 \mathrm{mg} /$ day), and a mood stabilizer (valproic acid $200 \mathrm{mg} /$ day).

During the peritoneal dialysis sessions, $1.5 \mathrm{~L}$ of dialysate (MIDPELIQ ${ }^{\circ} 135$ ) was administered to the patient twice from 12:00 to 18:00, and four times at 23:00-8:00. Hemodialysis was administered with an APS-21SA capillary dialyzer (membrane area, 2.1; Kindaly 4E; Fuso and a TR-3000MA (Toray Medical Co.) monitor was used; hemodialysis sessions lasted approximately $4 \mathrm{~h}$. Blood and dialysate flows were held constant at $200 \mathrm{ml} / \mathrm{min}$ and $500 \mathrm{ml} / \mathrm{min}$, respectively.

To study the effect of hemodialysis and peritoneal dialysis, on drug pharmacokinetics, the subject was hospitalized, and plasma and dialysate samples were collected, and the concentrations of RPV and DTG were assayed. Upon admission, laboratory examination revealed the serum albumin level to be $2.5 \mathrm{~g} / \mathrm{dL}$, and the patient had an undetectable HIV-1 RNA viral load and the CD4 lymphocyte count was 1000 cells $/ \mu \mathrm{L}$. A month after the introduction of a combination therapy of hemodialysis and peritoneal dialysis, current antiretroviral therapy maintained complete viral suppression.

DTG and RPV were administered to the patient once daily at 8:00 and 18:00, respectively. The patient's blood was sampled at 8:00, 12:00, 18:00, and 23:00. During peritoneal dialysis sessions, all dialysate was collected, and the concentrations of RPV and DTG were assayed. The dialysate was sampled at the following time points: 12:00-15:00 and 12:00-8:00 (Fig. 1). For hemodialysis, blood samples were collected at the beginning and end of a session. Additionally, paired samples of blood upon both entering (in) and leaving (out) the dialyzer were collected $1 \mathrm{~h}$ after starting the dialysis session. Spent dialysate collection was performed with a validated technique using a droplet pump to get a dialysate sample having a concentration representative of the concentration of the entire spent dialysate volume. Furthermore, all urine voided for $24 \mathrm{~h}$ was collected and tested for concentrations of RPV and DTG.

Blood samples were centrifuged at $3000 \mathrm{rpm}$ for 10 min, and plasma samples $(1 \mathrm{~mL})$ were collected and stored at $-80{ }^{\circ} \mathrm{C}$ until assayed. Five milliliters of dialysate samples were collected and stored at $-80{ }^{\circ} \mathrm{C}$ until being assayed. All samples were outsourced to BML Inc. (Tokyo, Japan) for measurement of the RPV and DTG concentrations using high-performance liquid chromatography.

The hemodialysis extraction ratio (ER) for RPV and DTG was calculated as previously described [6]: $\operatorname{ER}(\%)=$ (C pre-C post/C pre) $\times 100$; where "C pre" and "C post" are pre- and post-dialysis blood concentrations. Due to the high protein-binding abilities of RPV and DTG, postdialysis concentrations were corrected for hemoconcentration by a factor $F$ as based on total protein (TP) concentration for pre-dialysis (TP pre) and post-dialysis (TP post )[5]: $F=\mathrm{TP}$ in/TP out. Likewise, dialyzer outlet concentration was corrected by $F=\mathrm{TP}$ in/ TP out.

This study was performed with the permission of University of the Ryukyus ethics committee and was performed after sufficiently explaining its contents and aims to the patient and obtaining his consent to participate.

TP concentration pre-dialyzer (TP in) and postdialyzer (TP out) was $6.0 \mathrm{~g} / \mathrm{dL}$ and $6.2 \mathrm{~g} / \mathrm{dL}$, respectively. 


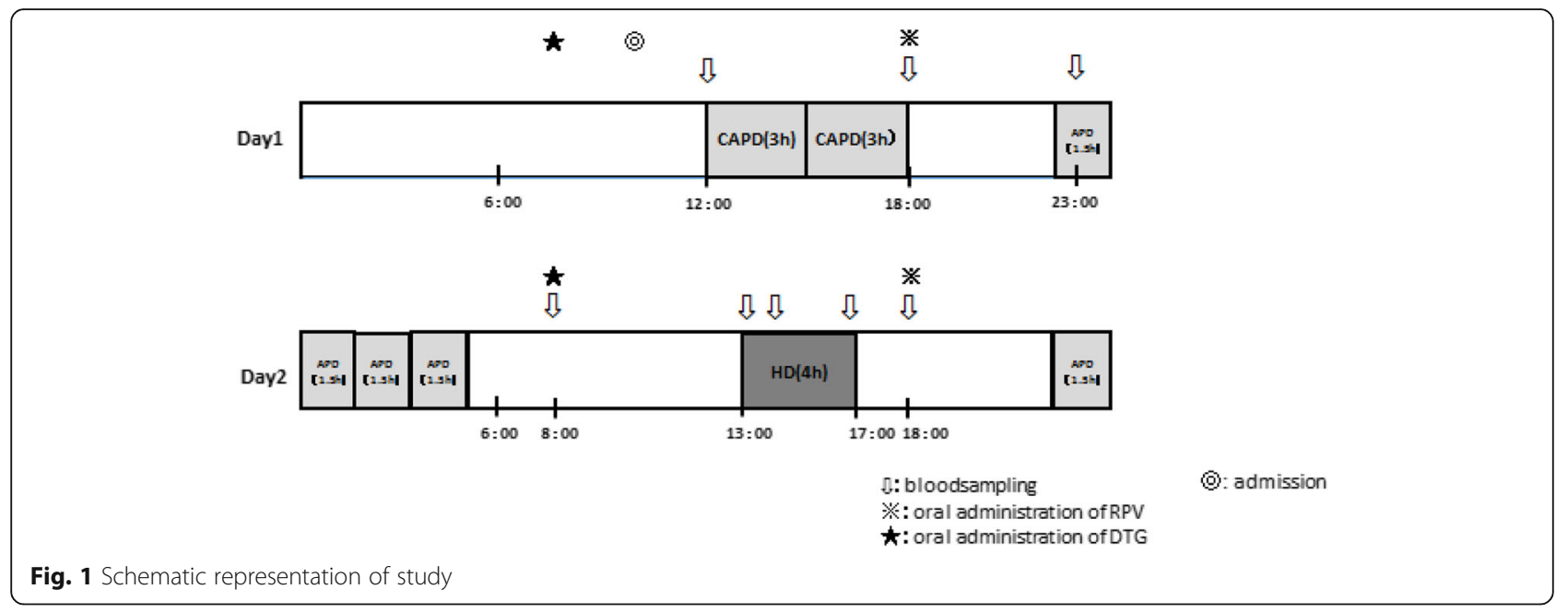

Moreover, TP concentration at state (TP pre) and end of the dialysis session (TP post) was $6.0 \mathrm{~g} / \mathrm{dL}$ and $6.5 \mathrm{~g} / \mathrm{dL}$, respectively. The amount of body fluid removed by hemodialysis was $1 \mathrm{~L}$.

Figure 2 summarizes the RPV concentrations in plasma and dialysate during hemodialysis. The hemodialysis ERs of RPV and DTG were $4.5 \%$ and $1.4 \%$, respectively, with negligible concentrations in the dialysate. The RPV concentrations in plasma at the end of the hemodialysis session remained at 4.1 times the proteinbinding-adjusted 90\% inhibitory concentration (IC90) against different strains of HIV, at $0.012 \mu \mathrm{g} / \mathrm{mL}$ [6]. Similarly, the RPV concentrations of plasma at the end of the hemodialysis session remained 2.6 times the protein-binding-adjusted IC90 for viral growth adjusted for the protein concentration at $0.064 \mu \mathrm{g} / \mathrm{mL}$ [8]. RPV concentration pre-dialyzer $(\mathrm{C}$ in) and post-dialyzer $(\mathrm{C}$ out) were $0.022 \mu \mathrm{g} / \mathrm{mL}$ and $0.024 \mu \mathrm{g} / \mathrm{mL}$, which showed the small differences between RPV concentrations in the plasma going in and coming out of the dialyzer machine.

Figure 2 also shows RPV concentrations in plasma and dialysate during peritoneal dialysis. Plasma levels for RPV remained far above the protein-binding-adjusted IC90 at $0.01 \mu \mathrm{g} / \mathrm{mL}$ at each time point analyzed during peritoneal dialysis. RPV was detected in the dialysate at a concentration of $0.005 \mu \mathrm{g} / \mathrm{mL}$.

The results of the present study suggest a negligible elimination of DTG within the hemodialysis dialysate, but we could not evaluate the effect of peritoneal dialysis on DTG clearance as the DTG concentration was consistently undetectable during peritoneal dialysis. The blood levels of DTG were below the protein-bindingadjusted IC90; therefore, we altered the cART regimen from including DTG to 3TC.

\section{Discussion and conclusions}

Administration of cART has remarkably reduced acquired immune deficiency syndrome (AIDS)-related deaths and related occurrence of opportunistic infectious diseases. However, such improvement in survival has been accompanied by an increase in the incidence of chronic kidney disease and ESRD in HIV/AIDS patients [3]. RPV is the latest non-nucleoside reverse transcriptase inhibitor shown to be active against HIV-1, and although it is being used for HIV-infected patients with ESRD, no data were previously available describing its related pharmacokinetics and safety in this patient population. To the best of our knowledge, this is the first case

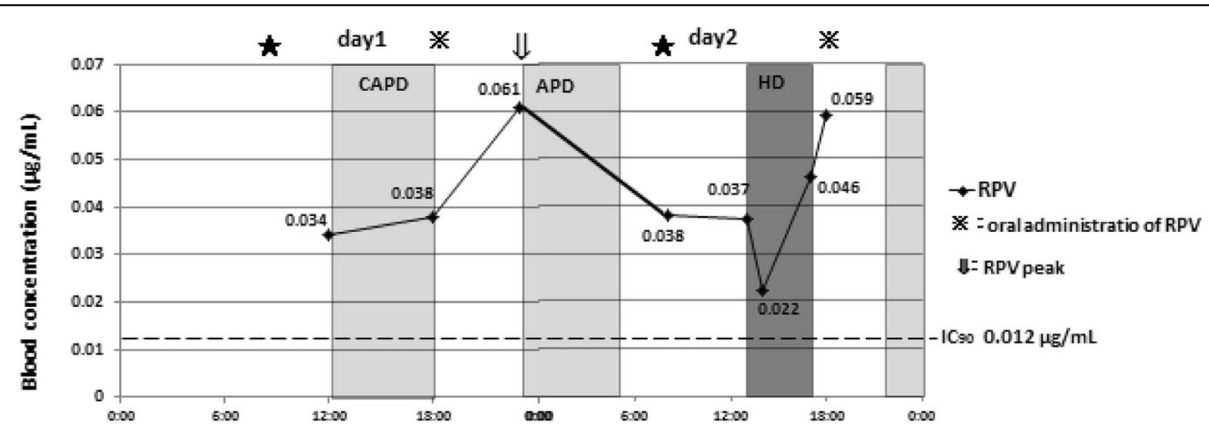

Fig. 2 RPV plasma concentrations during hemodialysis and peritoneal dialysis 
of an HIV-infected patient undergoing a combination therapy of peritoneal dialysis and hemodialysis whose RPV concentration was measured.

RPV is > 99\% bound to proteins within plasma and is minimally eliminated by the kidneys, with $<1 \%$ of the administered dose excreted in the urine $[7,8]$. In the case described here, plasma RPV concentration was maintained far above the level of the protein-bindingadjusted IC90 under the minimal ER of RPV during both hemodialysis and peritoneal dialysis. Therefore, adjustment of RPV dosage does not seem to be necessary in HIV-infected patients with ESRD who are undergoing such combined treatment. In general, the RPV concentration peaks 4-5 $\mathrm{h}$ after oral administration and decreases over time because of its metabolism in the liver. In our case, plasma concentration of RPV decreased after reaching maximum concentration before starting hemodialysis and reached the plateau stage just before starting hemodialysis. However, there was further decrease until the first hour after the starting dialysis. As RPV was not detectable in the dialysate, we believe the decrease in RPV concentration after initiating the hemodialysis session for $1 \mathrm{~h}$ may be due to the adsorption of this drug by the dialysis membrane, although we were unable to check this. It is reported that many drugs are adsorbed on the dialysis membranes. It has been proposed that there are two steps of plasma protein membrane adsorption [9]. The first occurs on the membrane surface as a result of preferential competitive adsorption of high-molecular weight protein, such as albumin. The second step of adsorption, which follows surface adsorption, is absorption in the body of the membrane of proteins with low- and medium-molecular weight proteins, such as $\beta 2$ microglobulin and cytokines. Moreover, the adsorption force of human serum albumin on the inner surface of the polysulfate membranes was reported to be higher than that on the inner surface of other types of membrane [10]. As more than $90 \%$ of RPV is bound to albumin in blood, we suppose that RPV may be also adsorbed on the dialysis membrane by albumin absorbed in this patient and resulted in acute reduction in its plasma concentration.

On the contrary, there was increase in the RPV concentration from $1 \mathrm{~h}$ after starting hemodialysis. At least this finding suggested that there was a supply of drug from somewhere into the blood. In general, the "rebound phenomenon," defined as the drug concentration rebounds and rise again could be observed in the drugs with high distribution volume. The rebound phenomenon is attributed to returning of drug to the blood from the redistributed tissue and could cause elevation of drug during hemodialysis session even in the drugs with high-dialytic removal rate [11]. The distribution volume and protein-binding ratio of RPV are as high as $401 \mathrm{~L}$ [7] and 99.7\%, respectively. The distribution volume of RPV may be further increased in this patient with hypoalbuminemia. Therefore, enhanced "rebound phenomenon" combined with saturation of the amount of drug adsorbed by the dialysis membrane may be responsible for the elevation of RPV concentration after starting hemodialysis.

Concerning DTG, Jose and colleagues reported minimal loss of this drug via hemodialysis [6]. Similarly, in the present study, there were little differences in DTG plasma concentration prior to and following dialysis, and DTG concentrations in dialysate were very low. Plasma concentrations of DTG were undetectable just before peritoneal dialysis. We speculate that failure to detect DTG may be due to the patient not taking the drug at home as prescribed prior to admission. More data is needed to determine whether DTG may be lost by peritoneal dialysis.

In conclusion, this study showed that RPV given without dose-adjustment resulted in maintaining plasma drug concentrations above the protein-binding-adjusted IC90 in an HIV-infected patient treated with a combination therapy of hemodialysis and peritoneal dialysis. However, we need to be aware of the possibility that RPV may be adsorbed by some dialysis membranes.

\section{Abbreviations \\ RPV: Rilpivirine; HIV: Human immunodeficiency virus; ESRD: End-stage renal disease; CART: Combined antiretroviral therapy; RRT: Renal replacement therapy; DTG: Dolutegravir; ER: Extraction ratio; TP: Total protein; IC90: 90\% inhibitory concentration}

\section{Acknowledgements \\ The authors wish to acknowledge and thank Dr. Hiroki Yagura (National Hospital Organization Osaka National Hospital) for measuring drug concentrations.}

\section{Authors' contributions}

$\mathrm{NO}, \mathrm{ST}, \mathrm{MT}, \mathrm{HU}$, and RZ contributed to the design and implementation of the research. NO, ST, and KK prepared the manuscript. MT, JF, and YO reviewed and revised the manuscript. All authors read and approved the final manuscript.

\section{Funding}

Not applicable.

\section{Availability of data and materials}

The data and materials were all included in the manuscript.

\section{Ethics approval and consent to participate}

All procedures performed in this case report were in accordance with the ethical standards of the institutional committee and with the 1964 Helsinki Declaration and its later amendments or comparable ethical standards.

\section{Consent for publication}

Written informed consent was obtained from the patient for publication of this case report and any accompanying images.

Competing interests

The authors declare that there is no conflict of interest. 


\section{Author details}

'Department of Cardiovascular Medicine, Nephrology and Neurology, Faculty of Medicine, University of the Ryukyus, Okinawa, Japan. ${ }^{2}$ Dialysis Unit University of the Ryukyus Hospital, Okinawa, Japan. ${ }^{3}$ Department of Medicine and Clinical Science, Graduate School of Medical Sciences, Kyushu University, Fukuoka, Japan. ${ }^{4}$ Department of Infectious, Respiratory, and Digestive Medicine, Graduate School of Medicine, University of the Ryukyus, Okinawa, Japan. ${ }^{5}$ University of the Ryukyus Faculty Medicine, Okinawa, Japan.

Received: 29 April 2020 Accepted: 15 July 2020

Published online: 03 August 2020

\section{References}

1. RaO TKS. Human immunodeficiency virus infection in end-stage renal disease patients. Semin Dial. 2003;16:233-44.

2. Schwartz EJ, Szczech LA, Ross MJ, et al. Highly active antiretroviral therapy and the epidemic of HIV+ end-stage renal disease. J Am Soc Nephrol. 2005; 8:2412-20.

3. Minoru A, et al. The number of HIV-infected patients undergoing chronic dialysis therapy in Japan — surveillance based on data obtained from AIDS core hospitals - (in Japanese). J J.pn Soc Dial Ther. 2017;50:621-7.

4. Tejinder SA, Neil C, James G, Shilpi K. Is dialysis modality a factor in survival of patients with ESPD and HIV-associated nephpathy? Am J of Kidney Dis. 2003:41:1060-4.

5. Izzedine H. Launay- Vacher V, Baumelou A, Deray G. An appraisal of antiretroviral drugs in hemodialysis. Kidney Int. 2001;60:821-30.

6. Molto J, Graterol F, Miranda C, et al. Removal of dolutegravir by hemodialysis in HIV-infected patients with end-stage renal disease. Antimicrob Agents Chemother. 2016;60:2564-6.

7. Aouri M, Barcelo C, Guidi M, et al. Population pharamacokinetics and pharmacogenetics analysis of rilpivirine in HIV-1-infected individuals. Antimicrob Agents Chemother. 2017;61:e00899-16.

8. Cottrell ML, Hadzic T, Kashuba AD. Clinical pharmacokinetic, pharmacodynamics and drug-interaction profile of the integrase inhibitor dolutegravir. Clin Pharmacokinet. 2013;52:981-94.

9. Chanard J, Lavaud S, Randoux C, et al. New insights in dialysis membrane biocompatibility: relevance of adsorption properties and heparin binding. Nephrol Dial Transplant. 2003;18:252-7.

10. Namekawa K, Fukuda M, Matsuda M. Nanotechnological characterization of human serum albumin adsorption on wet synthetic polymer dialysis membrane surfaces. ASAIO Journal. 2009;55:236-42.

11. Sowinski KM, Magner SJ, Lucksiri A, et al. Influence of hemodialysis on gentamicin pharmacokinetics, removal during hemodialysis, and recommended dosing. Clin J Am Soc Nephrol. 2008;3:355-61.

\section{Publisher's Note}

Springer Nature remains neutral with regard to jurisdictional claims in published maps and institutional affiliations.

\section{Ready to submit your research? Choose BMC and benefit from:}

- fast, convenient online submission

- thorough peer review by experienced researchers in your field

- rapid publication on acceptance

- support for research data, including large and complex data types

- gold Open Access which fosters wider collaboration and increased citations

- maximum visibility for your research: over $100 \mathrm{M}$ website views per year

At $\mathrm{BMC}$, research is always in progress.

Learn more biomedcentral.com/submissions 